\title{
Insulated Concrete Blocks Using Plastic Waste and Steel Fibers
}

\author{
Umair Khan $^{1}$, Qazi Sami Ullah ${ }^{2}$, M.Fawad Gul ${ }^{3}$, Iftikhar Ahmad ${ }^{4}$, Khawar Naveed Abbasi ${ }^{5}$ \\ ${ }^{1,3}$ Research Student, Center for Advance studies in Energy, University of Engineering and Technology, Peshawar, \\ Pakistan \\ ${ }^{2}$ Assistant professor, Dept. of Civil Engineering, University of Engineering and Technology, Pakistan. \\ ${ }^{4}$ Assistant Professor, Dept of Energy Research Center, Comsates University Islamabad, Lahore Campus. \\ ${ }^{5}$ Assistant professor, Dept. of Mechanical Engineering, Capital University of Science \& Technology, Pakistan. \\ umair221143@gmail.com ${ }^{1}$, Fawad9809701@gmail.com² \\ Received: 01 July, Revised: 07 July, Accepted: 09 July
}

\begin{abstract}
Plastic is used in abundance due to its various beneficial properties. All forms of consumed plastic become waste and require large areas of land for storage. The low biodegradability of plastic and its presence in large quantity negatively affects the environment. Researchers have developed numerous techniques to recycle plastic. However, each technique has its own demerits. Such as use of solid plastic waste as aggregates in concrete, affects the concrete mechanical properties. Therefore, the objective of this research work is to regain concrete strength by using steel fibers in combination with PET plastic aggregates and investigate its effect on mechanical and thermal insulation properties of concrete. Different specimen were tested for compressive and tensile strength to find out the effect of plastic aggregates incorporation as fine aggregates replacement on strength of concrete. There was noticeable decrease in the compressive and split tensile strength of concrete at $20 \%$ replacement of sand by PET plastic aggregates. Steel fibers were also added to the concrete mixes which increase the strength of concrete mixes. After getting satisfactory results of mechanical properties, finally specimen were tested for thermal insulation properties. Results showed that thermal conductivity of samples decrease considerably with addition of plastic aggregates and it leads to good insulation properties of concrete.
\end{abstract}

Keywords--- Concrete, Plastic, Aggregates, Mechanical, Analysis

\section{INTRODUCTION}

Plastics have become an inseparable and integral part of our lives. The amount of plastics consumed annually has been growing steadily. Its low density, strength, fabrication capabilities, long life, light weight, and low cost are the factors behind such phenomenal growth. Plastic waste has many harmful effects on environment and its proper disposal is essential. Landfilling is one approach for waste plastic disposal but it is dangerous due to its slow degradation rate. The waste mass may hinder the ground water flow and causes water contamination. Plastic waste also contains various toxic elements especially cadmium and lead, which can mix with rainwater and pollute soil and water. Due to high calorific value of plastic waste, incineration can also be used as a method of disposal. However, burning of plastic pollute the air by releasing numerous poisonous gases, including dioxins. Plastic can be recycled through different techniques but it is not an economically efficient process to recycle the plastic as it degrades in quality and needs some new plastic to produce the original product. Recycling of plastic waste to produce new materials, such as cement composites appears as one of the best solution for disposing of plastic waste due to its economic and ecological advantages

Although these disposal methods are feasible, recycling of plastic waste to produce new materials, such as cement composites, appears a best solution due to its ecological and economic benefits. Extensive work in recycling is already done on the use of plastic waste as polyethylene terephthalate (PET) bottle [1,2], high density polyethylene (HDPE) [3], poly vinyl chloride (PVC) pipe [4], shredded and recycled plastic waste [5], glass reinforced plastics (GRP) [6], expanded polystyrene foam (EPS) [7], polycarbonate [8], polypropylene fiber [9], polyurethane foam [10,11], a fiber or filler in the making of concrete. This paper investigates the effect of PET plastic aggregates in combination with steel fibers on mechanical and thermal insulation properties of concrete. The use of PET waste aggregates in concrete will help in disposal of wastes and, will also reduce the environmental damages caused by the use of natural mineral aggregates resources.

\section{EXPERIMENTAL}

\section{A. Materials}

Materials use in this study are Type 1 Portland cement, river sand, $3 / 4$ inch coarse aggregates and water. ASTM C33 was used to examine gradation of fine and coarse aggregates. PET aggregates were obtained from PET bottles. [12] Hooked shape steel fibers with dimensions $65 \mathrm{~mm}$ length and $.5 \mathrm{~mm}$ diameter were used. Mix design ratio of 1:2:4 was used with targeted strength of 20MPA. 


\section{B. Test Methods}

Twenty four cylinders ( $\mathrm{r}=3$ inch, $\mathrm{h}=12 \mathrm{inch})$ and 12 rectangular samples $(25 * 100 * 100) \mathrm{mm}$ were prepared. All specimens cured in water for 28 days. Cylinders were tested for compression and splitting tensile strength and rectangular samples were tested for thermal conductivity. UTM machine was used to determine Compressive and Split tensile strength. Thermal conductivity was calculated by thermal conductivity of building apparatus. After calculation of heat flux and temperature difference, Fourier's law was used to determine thermal conductivity. ASTM C39 was used for compressive strength, ASTM C496 was used for split tensile strength and ASTM C518 was use for thermal conductivity measurement.

\section{RESULTS AND DISCUSSION}

\section{A. Density}

Density of concrete is an important property and it depends on the amount and density of aggregates added along with air content and water and cement ratio. Results in $\mathrm{kg} / \mathrm{m}^{3}$ are shown in figure 1. Plastic aggregates are lighter than sand that is why there is a decrease in density upon addition of plastic aggregates.

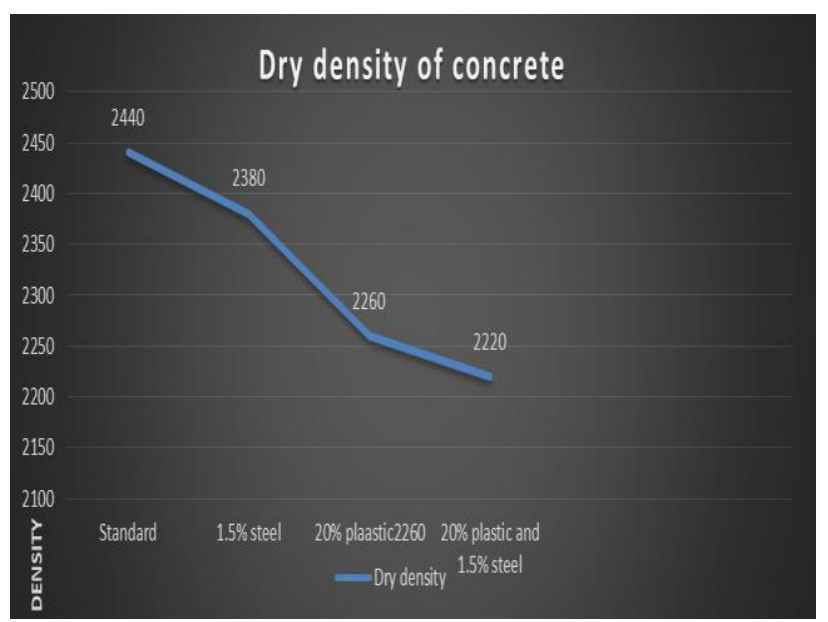

Figure 1 Density of different samples

\section{B. Compressive strength}

Compressive strength results at 28 days are shown in table I. Compressive strength decreases by $38 \%$ after replacing sand with $20 \%$ of plastic aggregates. This is attributed to the fact that adhesive forces are less between plastic surface and natural aggregates and lower strength of plastic aggregates.[13] Similarly after addition of $1.5 \%$ steel fibers there is $15 \%$ increase in compressive strength which can be attributed to good mechanical properties of steel.[14]

TABLE I. COMPRESSIVE STRENGTH RESULTS

\begin{tabular}{|c|c|c|}
\hline Type of sample & $\begin{array}{c}\text { Compressive Strength } \\
\text { (MPA) }\end{array}$ & Percentage change \\
\hline Standard & 18.64 & $0 \%$ \\
\hline
\end{tabular}

\begin{tabular}{|c|c|c|}
\hline $20 \%$ plastic & 11.71 & $-38 \%$ \\
\hline $1.5 \%$ Steel & 21.91 & $15 \%$ \\
\hline $\begin{array}{c}20 \% \text { plastic }+ \\
1.5 \% \text { Steel }\end{array}$ & 15.1 & $-19 \%$ \\
\hline
\end{tabular}

\section{Splitting Tensile Strength}

Results of split tensile strength are given in table II. Split tensile strength decreases by

$10 \%$ after replacing sand with $20 \%$ of plastic aggregates. Similarly after addition of $1.5 \%$ steel fibers there is $16 \%$ increase in split tensile strength which can be attributed to good mechanical properties of steel.

Final sample of concrete where both steel fibers and plastic aggregates are added show average strength of 6.75 MPA, with $4.4 \%$ decrease compared to control samples.

TABLE II. SPlitting TENSILE StREnGth RESUltS

\begin{tabular}{|c|c|c|}
\hline Type of sample & $\begin{array}{c}\text { Split Tensile Strength } \\
\text { (MPA) }\end{array}$ & Percentage change \\
\hline Stanadard & 6.96 & $0 \%$ \\
\hline $20 \%$ plastic & 6.27 & $-10 \%$ \\
\hline $1.5 \%$ Steel & 8.27 & $16 \%$ \\
\hline Final & 6.75 & $-4.4 \%$ \\
\hline
\end{tabular}

\section{Specific Heat}

Results of specific heat are shown in table IV. Results indicate that with addition of $20 \%$ plastic aggregate there is $13 \%$ increase in specific heat value. Decrease in specific heat value is just $1 \%$ with addition of $1.5 \%$ steel fibres.

TABLE III. SPECIFIC HEAT RESULTS

\begin{tabular}{|c|c|c|}
\hline S.No & Type of sample & C (J.Kg-1 .K-1) \\
\hline 1 & Control samples & 725 \\
\hline 2 & $20 \%$ Plastic & 828 \\
\hline 3 & $1.5 \%$ steel & 731 \\
\hline 4 & $20 \%$ Plastic+1.5\% steel & 810 \\
\hline
\end{tabular}

\section{E. Thermal Conductivity}

Results of thermal conductivity are shown in table III. Results show that with addition of plastic aggregates thermal conductivity decrease considerably. This can be attributed to the lower thermal conductivity and density of plastic aggregates as compared to natural sand. After the addition of $20 \%$ plastic aggregates, thermal conductivity decrease by $28 \%$. Addition of steel fibers increase thermal conductivity by $7.5 \%$ but due to $28 \%$ decrease because of plastic aggregates, final specimen have $17 \%$ decrease in the value of thermal conductivity. 
TABLE IV. THERMAL CONDUCTIVITY RESULTS

\begin{tabular}{|c|c|c|}
\hline Type of sample & $\begin{array}{c}\text { Thermal conductivity } \\
(\mathbf{W m - 1} \text { K-1) }\end{array}$ & Percentage change \\
\hline Stanadard & 1.31 & $0 \%$ \\
\hline $20 \%$ plastic & .94 & $-28 \%$ \\
\hline $1.5 \%$ Steel & 1.40 & $7.5 \%$ \\
\hline $\begin{array}{c}20 \% \text { plastic and } \\
1.5 \% \text { Steel }\end{array}$ & 1.09 & $-17 \%$ \\
\hline
\end{tabular}

\section{CONCLUSION}

The following conclusion can be drawn from this research.

1. The dry density of concrete decreases with addition of plastic aggregates as replacement of sand, which means it can be used as light weight concrete.

2. The compressive strength decreases with incorporation of $20 \%$ plastic aggregates, but with addition of $1.5 \%$ steal fibers some lose in strength is recovered. Compressive strength decreases by $38 \%$ with incorporation of $20 \%$ plastic and increases by $15 \%$ with incorporation of $1.5 \%$ steel fibers.

3. The splitting tensile strength also decreases with plastic aggregates, but this decrease is much smaller compared to compressive strength. Splitting tensile strength decreases by $10 \%$ with incorporation of $20 \%$ plastic and increases by $16 \%$ with incorporation of $1.5 \%$ steel fibers.

4. Plastic has low thermal conductivity compared to concrete. Thermal conductivity of concrete will decreases with addition of plastic aggregates, which means it will provide better insulation in building compared to normal concrete. After the addition of $20 \%$ plastic aggregates, thermal conductivity decreased by $28 \%$. There is a slight increase of $7.5 \%$ in thermal conductivity with incorporation of $1.5 \%$ steel fibers. On the other hand specific heat increases with addition of plastic aggregates. Specific Heat Increases with Incorporation of plastic aggregates. Overall our final specimen shows much better insulation properties compared to standard concrete.

\section{ACKNOWLEDGEMENT}

I am very thankful to my supervisor Dr.Qazi Sami Ullah for his sincere counseling and guidance. I am also thankful to Dr.Khawar Naveed for allowing thermal testing on the apparatus available in CUST Islamabad. I would also like to thank Dr. Iftikhar Ahmed for his counseling.

\section{REFERENCES}

[1] Cordoba, L.A., Berrera, G.M., Diaz, C.B., Nunez, F.U., Yanez, A.L., 2013. Effects on mechanical properties of recycled PET in cement-based composites. Int. J. Polym. Sci. 2013, 1e6

[2] Araghi, H.J., Nikbin, I.M., Reskati, S.R., Rahmani, E., Allahyari, H., 2015. An experimental investigation on the erosion resistance of concrete containing various PET particles percentages against sulfuric acid attack. Constr. Build. Mater. 77, 461e471.
[3] Naik, T.R., Singh, S.S., Huber, C.O., Brodersen, B.S., 1996. Use of post-consumer waste plastic in cement-based composites. Cem. Concr. Res. 26, 1489e1492.

[4] Kou, S.C., Lee, G., Poon, C.S., Lai, W.L., 2009. Properties of lightweight aggregate concrete prepared with PVC granules derived from scraped PVC pipes. Waste Manag. 29, 621e628.

[5] Bhogayata, A., Shah, K.D., Arora, N.K., 2013. Strength properties of concrete containing post-consumer metalized plastic wastes. Int. J. Eng. Res. Technol. ISSN: 2278-0181 2 (3).

[6] Asokan P, Osmani M, Price ADF. Improvement of the mechanical properties of glass fibre reinforced plastic waste powder filled concrete. Constr Build Mater 2010;24:448-60

[7] Kan A, Demirbog a R. A novel material for lightweight concrete production. Cem Concr Compos 2009;31:489-95.

[8] Hannawi K, Kamali-Bernard S, Prince W. Physical and mechanical properties of mortars containing PET and PC waste aggregates. Waste Manage 2010;30:2312-20

[9] Bayasi Z, Zeng J. Properties of polypropylene fiber reinforced concrete. ACI Mater J 1993;90:605-10

[10] Fraj AB, Kismi M, Mounanga P. Valorization of coarse rigid polyurethane foam waste in lightweight aggregate concrete. Constr Build Mater 2010;24:1069-77

[11] Mounanga P, Gbongbon W, Poullain P, Turcry P. Proportioning and characterization of lightweight concrete mixtures made with rigid polyurethane foam wastes. Cem Concr Compos 2008;30:806-14

[12] Van Krevelen, D.W., 1990. Properties of Polymers, Elsevier, Amsterdam, The Netherlands, 1990.

[13] Al-Manaseer, A.A., Dalal, T.R., 1997. Concrete containing plastic aggregates. Concrete International 19 (8), 47-52.

[14] Klein, R. Laser Welding of Plastics, 1st ed.;Wiley-VCH: Hoboken, NJ, USA, 2011

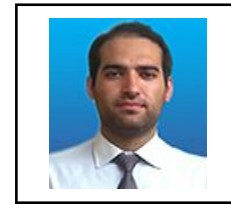

Umair Khan who graduated from Ghulam Ishaq khan Institute of engineering sciences and technology in 2015. He holds B.S degree in Mechanical Engineering. $\mathrm{He}$ is currently postgraduate student in M.Sc Materials for Energy Storage and Conversion (MESC) at US Pakistan Center for Advanced Studies in Energy (USPCASE) UET Peshawar. 